
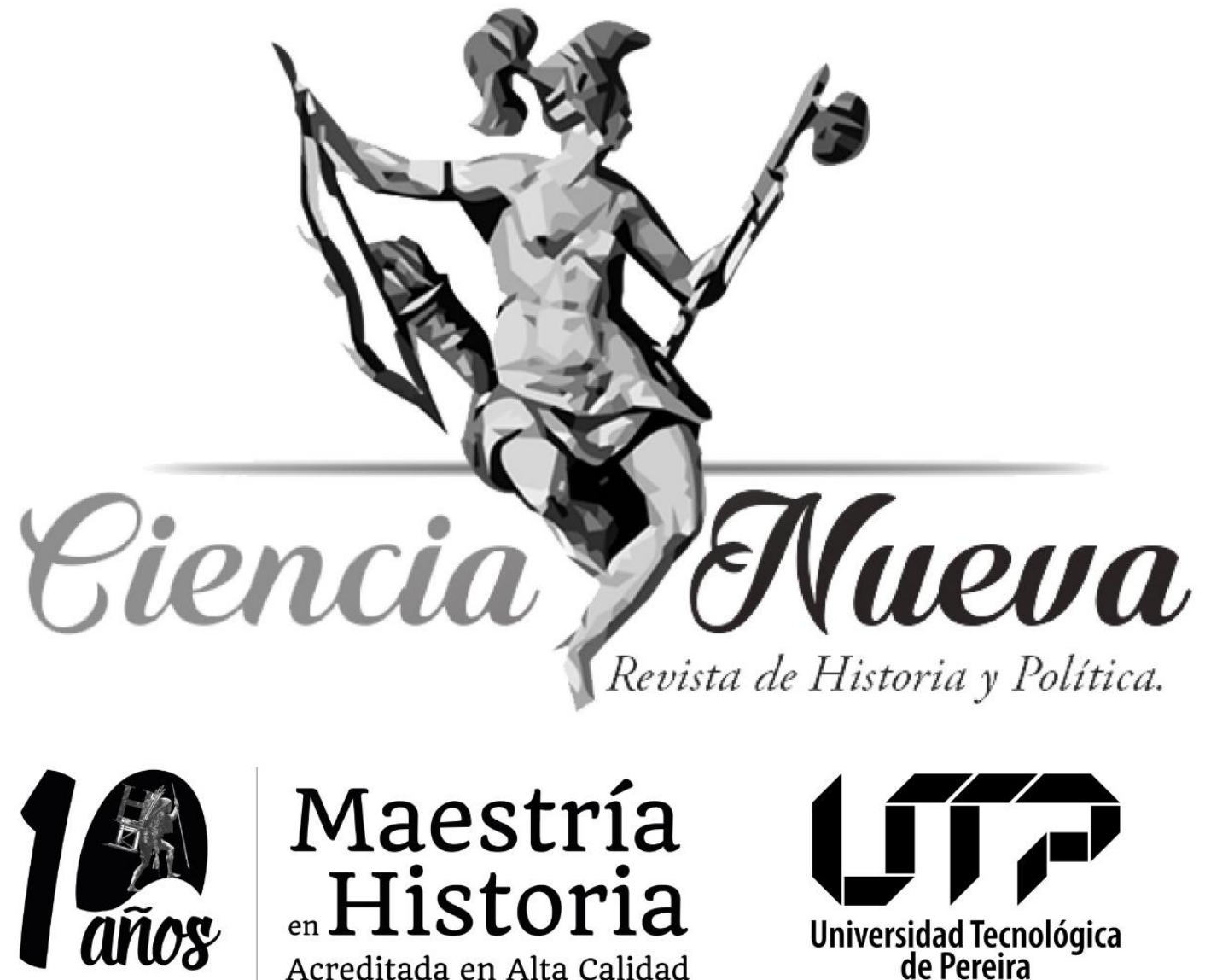

Maestría enHistoria Acreditada en Alta Calidad

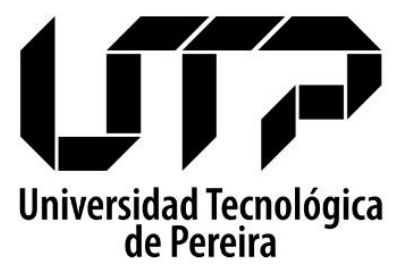

DOSSIER

APUNTES SOBRE LA MIGRACIÓN FORZADA COLOMBIANA. APORTES PARA LA VERDAD SOBRE EL EXILIO NOTES ABOUT COLOMBIAN FORCED MIGRATION. CONTRIBUTIONS TO THE TRUTH ABOUT EXILE

Diana Patricia Ortiz Camargo y Mauricio Viloria pp. 174-193

DOI: https://doi.org/10.22517/25392662.24523

Vol. 4 Núm. 2 | Julio-diciembre de 2020

Pereira, Colombia

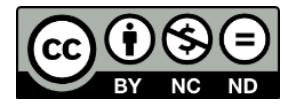




\title{
APUNTES SObre la Migración FORZAda COLOMbiana. APORTES PARA LA VERDAD SOBRE EL EXILIO*
}

\author{
NOTES ABOUT COLOMBIAN FORCED MIGRATION. CONTRIBUTIONS TO THE TRUTH ABOUT \\ EXILE
}

Diana Patricia Ortiz Camargo**

dportiz.c@gmail.com

ORCID: http://orcid.org/0000-0003-1979-6662

Mauricio Viloria***

mauricio@ caref.org.ar

ORCID: https://orcid.org/0000-0002-7333-1009

$\begin{array}{cc}\text { Recibido: } & 09 \text { de octubre de } 2020 . \\ \text { Revisado: } & 11 \text { de noviembre de } 2020 . \\ \text { Aceptado: } & 17 \text { de noviembre de } 2020 . \\ \text { Publicado: } & 31 \text { de diciembre de } 2020 .\end{array}$

\section{Resumen}

Este artículo propone algunas reflexiones en torno al trabajo extraterritorial de la Comisión para el Esclarecimiento de la Verdad, la Convivencia y la No Repetición con el exilio colombiano. El escrito se compone de seis apartados. Los dos primeros presentan una breve introducción a las dinámicas de la migración colombiana en el siglo XXI y ofrecen una breve reseña histórica y demográfica de la migración forzada colombiana a partir de la segunda mitad del siglo pasado. La tercera parte plantea una aproximación a los conceptos de víctimas en el exterior, exilio y refugio desde las dimensiones del derecho positivo y la politicidad, como un marco analítico para el exilio colombiano. La cuarta y quinta parte abordan la experiencia de la Comisión Verdad y Justicia del Paraguay, en su trabajo sobre el exilio como una violación a los derechos humanos, para identificar elementos problematizadores del despliegue extraterritorial e identificar los desafíos que enfrenta la Comisión de la Verdad en Colombia. Finalmente se registran algunas reflexiones a modo de conclusión.

Palabras claves: migración forzada, exilio, refugio, politicidad.

* 2 de diciembre de 1786, Archivo General de la Nación (AGN), Bogotá, Sección Colonia, Fondo Milicias y Marina, tomo 33, Doc. 5, folios 326r-335v. Este documento respeta las directrices y normas dispuestas en la Declaración de Ética de Publicación de Ciencia Nueva, Revista de Historia y Política. Esta declaración puede consultarse en la página web de la revista: http://revistas.utp.edu.co/index.php/historia

** Docente e investigadora en temáticas relacionadas a la movilidad humana con experiencia en Colombia, Ecuador y Argentina. Actualmente vinculada a la Universidad Nacional de José C. Paz de Argentina. Con formación de base en Matemáticas y Estadística y estudios de posgrado en Educación, Demografía y Ciencias Sociales. Como exiliada e integrante del colectivo Migrantes y Exiliadxs Colombianxs por la Paz (MECoPa, Argentina), acompaña el despliegue extraterritorial de la Comisión para el Esclarecimiento de la Verdad, la Convivencia y la No Repetición en el Cono Sur y la documentación de casos de personas dadas por desaparecidas en el marco del conflicto, y cuyos familiares residen en Chile y Argentina.

*** Trabajador social, integrante del Colectivo Migrantes y Exiliadxs Colombianxs por la Paz MECoPa y miembro coordinador de la Red de Víctimas Colombianas por la Paz REVICPAZ-LAC. Docente e investigador sobre desplazamiento forzado interno en Colombia. Trabaja en atención directa a personas migrantes y con necesidades de protección internacional con organizaciones de la sociedad civil en Argentina desde hace más de cinco años. 


\section{Abstract}

This article proposes a reflection on the extraterritorial work of the Commission for the Clarification of the Truth, Coexistence and Non-Repetition with Colombians in exile. The work is divided into six sections. The first two sections introduce the dynamics of Colombian migration in the 21st century and offer a brief historical and demographic review of Colombian forced migration from the second half of the last century. The third part examines the concepts of victims abroad, exile, and refuge from positive law and politics dimensions, as an analytical framework to study Colombians in exile. The fourth and fifth parts address the experience of the Paraguay Comissión of Truth and Justice and its work on exile as a violation of human rights. This is useful to identify not only problematizing elements of the extraterritorial deployment but also the challenges faced by the Truth Commission in Colombia. Finally, some reflections are given in a form of conclusion.

Keywords: forced migration, exile, refuge, politicity.

\section{Aspectos generales de la migración}

Este artículo pone en diálogo la revisión de fuentes secundarias, las reflexiones surgidas en trabajo de campo y la participación de sus autores en el despliegue extraterritorial de la Comisión para el Esclarecimiento de la Verdad, la Convivencia y la No Repetición en el Cono Sur. Desarrolla una perspectiva que valoriza las experiencias y reflexiones vividas y narradas por la propia población víctima de la migración forzada y del exilio en su heterogeneidad y desarrolla una mirada que busca aportar elementos de análisis en la comprensión de la complejidad de estos fenómenos sin invisibilizar ningún grupo poblacional afectado.

El Eje Cafetero, Valle del Cauca y Antioquia son las regiones del país que presentan las mayores tasas de emigración. Una migración tradicionalmente asociada a variables de tipo económico. Sin embargo, como en todo el territorio nacional, este fenómeno está relacionado con los contextos de crisis derivados de una violencia sociopolítica multiforme y sostenida.

El siglo XXI trajo notorios cambios en las dinámicas migratorias colombianas, marcando un acento significativo en los flujos sur-sur. El endurecimiento de las medidas migratorias y en los mecanismos de protección internacional en el norte global, tras los atentados del 11s, influyeron por vía de la restricción. La implementación del Plan Colombia en zonas de fronteras y los incrementos de la conflictividad generaron importantes movimientos de migración forzada transnacional. Por otra parte, las medidas adoptadas por la Comunidad Andina de Naciones, CAN, como la Tarjeta Andina y el Acuerdo de Residencia de los países miembros y asociados del Mercado Común del Sur, MERCosur, jugaron, por vía afirmativa, un papel determinante en estas transformaciones.

Entre los nuevos destinos de la población colombiana emigrante, empezaron a figurar con fuerza los países del sur del continente. Chile y Argentina se unieron a la lista que encabezaban Venezuela y Ecuador. A la vez que se redujeron los flujos hacia Venezuela, aumentaron por la frontera terrestre hacía Ecuador ${ }^{1}$, dinámica que puede observarse hasta nuestros días ${ }^{2}$.

\footnotetext{
1 Departamento Administrativo Nacional de Estadística, Anuario Estadístico 2002-2003. Movimientos migratorios internacionales de Colombia (Bogotá: DANE, 2004).

2 «Anuario estadístico de movimientos internacionales. Información 2018», Departamento Administrativo Nacional de Estadística, acceso el 23 de noviembre de 2020, https://www.dane.gov.co/index.php/estadisticas-
} 
Desde la década de los ochenta, se sostiene una tendencia de saldos migratorios negativos $^{3}$. Según cifras del último Censo Nacional de Población y Vivienda el $36 \%$ de los hogares colombianos declararon tener hijos viviendo fuera de Colombia ${ }^{4}$, esto equivale a cerca de cuatro millones y medio de personas, que representa el $10 \%$ de la población. Una cuarta parte se encuentra en los países del extremo sur del continente ${ }^{5}$.

Cifras ilustrativas que permiten dimensionar el impacto de la migración en la sociedad colombiana. Desde la década de los 60, la bonanza petrolera venezolana y el sueño americano alimentaron las promesas de prosperidad, de «movilidad social»o «prosperidad económica» de las familias que permanecen en el país. Se configura una narrativa en torno a la migración vigente hasta el presente, que minimiza los contextos de exclusión y xenofobia del migrante y oculta los desplazamientos forzados, pero que resalta a «Colombia como mayor receptor de remesas en Sudamérica» ${ }^{6}$.

Por otra parte, la Oficina del Alto Comisionado de las Naciones Unidas para los Refugiados, ACNUR, estimó en la primera década del siglo XXI, que cerca de medio millón de personas de origen colombiano tenían necesidades de protección internacional. Población altamente concentrada en Ecuador, Venezuela, Costa Rica y Panamá. Cifras que a finales de la segunda década disminuyeron considerablemente. Tendencia que, lejos de responder a la reducción de la migración forzada, se explica por el desistimiento o abandono del procedimiento, dada la debilidad de los sistemas de protección en la región y el largo y engorroso procedimiento para acceder al estatus de refugio.

$\mathrm{Si}$ se consideran las cifras generales de emigración, cerca del $10 \%$ puede caracterizarse como migración forzada. De la población emigrada a los países de Suramérica este porcentaje ronda el $25 \%$.

\section{Migración forzada colombiana, aproximaciones históricas y demográficas}

Hugo y Bun Kwork proponen tres categorías migratorias vinculadas al nivel de voluntariedad que interviene en el movimiento: i) migración libre, donde es decisoria la voluntad individual, ii) migración obligada cuando existe algún poder de decisión y iii) migración forzada si no hay posibilidad de decidir ${ }^{7}$. Resultan útiles estas categorías para

por-tema/demografia-y-poblacion/movilidad-y-migracion/anuarios-estadisticos-de-movimientos-

internacionales

3 Organización para la Cooperación y el Desarrollo Económico, OCDE, Migración Internacional en las Américas. Cuarto Informe del Sistema Continuo de Reportes sobre Migración Internacional en las Américas (SICREMI), (OEA: Washington D. C., 2017).

4 «Censo Nacional de Población y Vivienda 2018», Departamento Administrativo Nacional de Estadística, acceso el 23 de noviembre de 2020, https://www.dane.gov.co/index.php/estadisticas-por-tema/demografia-ypoblacion/censo-nacional-de-poblacion-y-vivenda-2018/herramientas

${ }_{5}$ Organización Internacional para las Migraciones, Informe Migratorio Sudamericano No. 1 (IOM, 2017), https://robuenosaires.iom.int/sites/default/files/Documentos\%20PDFs/Informe_Tendencias_Migratorias_Am \%C3\%A9rica_del_Sur_N1_SP.pdf

«Estadísticas Migraciones», Departamento de Extranjería y Migraciones de Chile, acceso del 20 de junio https://www.extranjeria.gob.cl/estadisticas-migratorias/

«Estadísticas Migraciones», Dirección Nacional de Migraciones de Argentina, acceso del 20 de junio de 2020, https://www.argentina.gob.ar/interior/migraciones/estadisticas

«Estadísticas Migraciones», Dirección Nacional de Migraciones de Uruguay, acceso 20 de junio de 2020 https://migracion.minterior.gub.uy/index.php/estadisticas

${ }^{6}$ OCDE, Migración Internacional en las Américas..., 88.

${ }^{7}$ Graeme Hugo y Chan Bun Kwok, «Conceptualizing and Defining Refugee and Forced Migrations in Asia», Southeast Asian Journal of Social Science 18, n. ${ }^{\circ} 1$ (1990). 
diferenciar los impactos que conlleva la migración. Si bien toda migración implica rupturas y sentimiento de desarraigo, el nivel de voluntariedad agrava su impacto. La migración libre, generalmente lleva consigo la construcción de un proyecto de vida de corto, mediano o largo plazo; la migración forzada, al contrario, rompe abruptamente con el proyecto de vida de quienes se ven afectados por ella.

Colombia ha sido históricamente un país expulsor, pese a que entre 1820 y 1830 , entregó 2,4 millones de hectáreas de tierra a empresas extranjeras asociadas con colombianos, «para favorecer sin éxito la inmigración de extranjeros» ${ }^{8}$. Proyectos que, en los países del Cono Sur, atrajeron efectivamente la migración europea y construyeron proyectos políticos modernizadores de distinto tinte y magnitud.

Los efectos de estos impactos constituyen una de las grandes diferencias de Colombia con aquellos países que desarrollaron políticas migratorias en América Latina, después de 1850. A la ausencia de nuevas ideas y de una vocación por universalizar lo local se debe, en gran parte, el espíritu conservador de nuestras clases dirigentes. Su capacidad de manipular las políticas de Estado y su predisposición a preservar, aún a costa de la guerra, viejas estructuras de poder económico y político9 .

La migración interna forzada ha sido una constante en la historia de Colombia. Después de la primera mitad del siglo pasado empezó a traspasar las fronteras nacionales. Tovar hace un rápido recorrido desde el siglo XVI, con la conquista, pasando por el siglo XIX con las guerras de independencia, la colonización antioqueña y otras de menor renombre, La Violencia (1948-1964) y el último período de grandes flujos que iniciaron a finales del siglo pasado ${ }^{10}$.

La emigración masiva atraída por la industrialización y modernización que se impulsó en los primeros años del siglo XX en las ciudades fue seguida por el desplazamiento forzado interno en época de La Violencia ${ }^{11}$. Las migraciones forzadas suelen seguir las rutas construidas previamente por la migración voluntaria y apoyarse en las redes vinculares generadas durante el proceso de movilidad. El censo de 1964 dio cuenta de una migración interna del $71 \%$, principalmente masculina, del campo a la ciudad.

En la segunda mitad del siglo pasado, se empezaron a registrar saldos migratorios internacionales negativos. El Departamento Administrativo Nacional de Estadística estimó, a partir del método hijos sobrevivientes en el exterior de Somoza y Hill, que 192.377 personas colombianas se encontraban fuera del país para 1960, cifra equivalente al $1 \%$ de la población total $^{12}$. Estados Unidos, Venezuela y Ecuador fueron los principales destinos de esta migración $^{13}$.

\footnotetext{
${ }^{8}$ Helmer, Tovar. Que nos tengan en cuenta. Colonos, empresarios y aldeas: Colombia 1800-1900 (Bogotá, Tercer Mundo Editores, 1995): p.44-48.

${ }^{9}$ Hermes Tovar, «Emigración y éxodo en la historia de Colombia», Amérique Latine Histoire et Mémoire 3, (2006), 2, doi: https://doi.org/10.4000/alhim.522 .

${ }^{10}$ Tovar, «Emigración y éxodo en la historia de Colombia».

${ }^{11}$ Ramiro Cardona, Las migraciones internas (Bogotá: Editorial Andes, 1968).

12 DANE, Estudios Postcensales. Estimación de la migración 1975-2005 (Bogotá: DANE, 2008), acceso el 23 de $\begin{array}{lll}\text { noviembre de 2020, } & \text { de }\end{array}$ https://www.dane.gov.co/files/investigaciones/poblacion/migraciones/doc_est_mig_1973_2005.pdf

${ }_{13}$ William Mejía, «Colombia y las migraciones internacionales. Evolución reciente y panorama actual a partir de las cifras», Revista Interdisciplinar da Mobilidade Humana XX, n. 39 (2012): 185-210.
} 
Los registros censales de 1950 y 1960 de los Estados Unidos dan cuenta de un incremento intercensal de cuatro veces ${ }^{14}$. Se estima que entre 1963 y 1973 medio millón de colombianos abandonaron el país ${ }^{15}$. Este cambio significativo en la emigración propició, a partir del censo de 1973, que se incluyeran preguntas referidas a la migración.

Este periodo de alta convulsión social, política y económica correspondió al contexto del Frente Nacional ${ }^{16}$, caracterizado por ciclos de violencia que incluyen, la desmovilización de las guerrillas liberales, el asesinato posterior de sus máximos representantes y el surgimiento de los principales movimientos insurgentes que sobrevivieron por más de cincuenta años ${ }^{17}$. Las protestas sociales son también protagonistas de la época, se reivindicaron mejoras en las condiciones laborales y salariales ante una inflación superior al $30 \%$. Las movilizaciones estudiantiles, la represión generalizada y la militarización de las universidades desembocaron en el Paro Cívico de $1977^{18}$.

En la década de los ochenta, se hizo evidente la migración forzada con destino predominante hacia Europa ${ }^{19}$, estrechamente vinculada a la violencia política. La instalación de diálogos de paz, que se desenvolvieron entre rupturas y acuerdos en la década comprendida entre la segunda mitad de los ochenta y la primera de los noventa ${ }^{20}$, dieron lugar a movimientos y partidos políticos como la Unión Patriótica, A Luchar, El Frente Popular y la Alianza Democrática M-19, a los que se sumaron otros de carácter regional, que pronto fueron victimizados por la represión estatal y una violencia paramilitar imbricada con el narcotráfico ${ }^{21}$.

Entre las posibles razones que pudieron haber dado lugar al surgimiento de este nuevo destino, estaría el apoyo activo de redes internacionales como Brigadas de Paz, Amnistía Internacional, partidos y movimientos del espectro progresista europeo, que acompañaban a las nacientes fuerzas y movimientos políticos alternativos y la búsqueda de salidas

\footnotetext{
${ }^{14}$ William Mejía, «Casi dos siglos de migración colombiana a Estados Unidos», Papeles de Población 24, n. ${ }^{\circ}$ 98 (2019).

${ }^{15}$ Lelio Mármora, «El Desarrollo de la Política de Migraciones Laborales en Colombia», en Migraciones Laborales 1 (Bogotá, D.C.: Senalde-Ministerio de Trabajo y Seguridad Social de Colombia, Proyecto PNUDOIT Migraciones Laborales, 1976).

${ }^{16}$ El Frente Nacional (1958-1974) fue un acuerdo bipartidista para la alternancia en el poder (liberales y conservadores) so pretexto de poner fin al periodo de La Violencia.

${ }^{17}$ Entre las principales guerrillas surgidas en la segunda mitad de la década del sesenta se destacan: las Fuerzas Armadas Revolucionarias de Colombia, FARC, (1964); el Ejército de Liberación Nacional, ELN, (1965); el Ejército Popular de Liberación Nacional, EPL, (1967) y el Movimiento 19 de Abril M-19 (1974).

${ }^{18}$ Mauricio Archila, «El paro cívico nacional del 14 de septiembre de 1977. Un ejercicio de memoria colectiva», Revista de Economía Institucional 18, n. ${ }^{\circ} 35$ (2016), doi: https://doi.org/10.18601/01245996.v18n35.18

${ }^{19}$ Con esta afirmación no se pretende desconocer que previo a la década de los ochenta también hubo población expulsada al exilio, solo que es en esta década que empieza a cobrar relevancia por el notorio incremento en la magnitud.

${ }^{20}$ Entre 1982 y 1987, se instalaron mesas de diálogos entre el estado colombiano y la insurgencia de las Fuerzas Armadas Revolucionarias de Colombia, FARC, en la Uribe, Meta, proceso en el que surge la Unión Patriótica, partido que daría el paso a la legalidad, una vez firmado el acuerdo de paz, y conversaciones con la Coordinadora Guerrillera Simón Bolívar (1987-1994) en la que confluían, las FARC, el ELN, el EPL, el M-19, el Partido Revolucionario de los Trabajadores (PRT) y el Movimiento Armado Quintín Lame. Durante los primeros años de la década de los noventa firmaron acuerdos de paz con el Estado, las cuatro últimas guerrillas mencionadas y una facción del ELN conocida como Corriente de Renovación Socialista.

21 Centro Nacional de Memoria Histórica, Paramilitarismo. Balance de la contribución del CNMH al esclarecimiento histórico (Bogotá, CNMH, 2018a). CNMH, Todo pasó frente a nuestros ojos. El genocidio de la Unión Patriótica 1984-2002 (Bogotá, CNMH, 2018b).
} 
negociadas al conflicto. A finales del siglo pasado, España se ubicó entre los cinco principales destinos de población colombiana.

La Constitución de 1991 posibilitó importantes transformaciones políticas, entre otras, la elección popular de autoridades regionales y locales y puso límites al estado de sitio, una práctica habitual de los gobiernos del Frente Nacional y sus herederos inmediatos, con las que se habilitó la designación de autoridades militares para el ejercicio de la administración pública. Las nuevas fuerzas políticas accedieron a cargos de representación local, regional y nacional, con el respaldo de bases sociales excluidas o no representadas por las formaciones políticas hasta ahora existentes.

Los primeros ejercicios de gobierno de estas nuevas expresiones fueron leídos por los poderes tradicionales como un factor desestabilizante del orden social imperante. En este contexto se desencadenó contra ellas una violencia política sistemática, primero contra figuras reconocidas de la vida pública como concejales, diputados, alcaldes, senadores y candidatos presidenciales ${ }^{22}$, para ampliar posteriormente su radio de acción contra la militancia de base ${ }^{23}$.

Los movimientos y partidos políticos que para entonces existían recibieron el nuevo siglo profundamente debilitados, unos por aniquilamiento, otros porque sus prácticas tradicionales y hegemónicas eran vetustas y sus consensos internos demasiado frágiles. Los altos niveles de violencia política coincidieron con la profundización, escalamiento y degradación del conflicto, los impactos sufridos motivaron en la opinión pública nuevas presiones para la instalación de otra etapa de diálogos de paz, a finales de la década de los noventa ${ }^{24}$.

La metodología de estas nuevas mesas incluyó espacios de participación para los movimientos sociales, en las que se visibilizaron problemáticas y demandas referidas a derechos humanos, económicos, sociales, políticos y culturales.

La ruptura de los diálogos y la asunción presidencial de Uribe Vélez evidenció reconfiguraciones y profundizaciones de las dinámicas represivas en el ejercicio del control territorial. Aunque los líderes de oposición más visibles a nivel nacional y regional siguieron sufriendo amenazas, los homicidios y atentados contra ellos sugieren una tendencia decreciente. Mientras que los homicidios, atentados y la persecución judicial con fines políticos contra liderazgos más vinculados a agendas locales y territoriales aumentaron considerablemente y se sosteniente hasta el presente.

Una nueva oleada de desplazamiento forzado interno similar al sufrido durante el periodo conocido como La Violencia, por su impacto y magnitud en proporción a la población total, se visibilizó a nivel nacional e internacional. En lo corrido del siglo alcanzó cifras escandalosas que superan los 8 millones. Desde hace varios años Colombia figura en

\footnotetext{
${ }^{22}$ Entre 1984 y 2002, la violencia contra la UP por grupos paramilitares y miembros de las fuerzas de seguridad del Estado (Ejército, Policía e Inteligencia) dejó más de 4000 militantes asesinados o desaparecidos, entre ellos 2 candidatos presidenciales, 5 congresistas en ejercicio, 11 diputados, 109 concejales, varios exconcejales, 8 alcaldes en ejercicio, 8 exalcaldes, CNMH, Paramilitarismo.... En 1997 la Comisión Interamericana de Derechos Humanos declaró admisible el pedido, presentado por REINICIAR y la Comisión Colombiana de Juristas, sobre la constitución del delito de genocidio político por parte del Estado colombiano, en el caso de la UP.

23 Centro Nacional de Memoria Histórica, Paramilitarismo. Balance de la contribución del CNMH al esclarecimiento histórico (Bogotá, CNMH, 2018a).

${ }^{24}$ A finales de los noventa e inicios del nuevo siglo el estado colombiano instalo mesas de diálogos con las FARC (Diálogos del Caguán) y con el ELN (Convención Nacional y la Cumbre por la Paz).
} 
los reportes de tendencias globales de ACNUR, como el país con más alto nivel de desplazamiento interno forzado ${ }^{25}$.

El despojo de tierras y territorios y el control de recursos estratégicos para economías legales e ilegales van apareciendo como causas explicativas del fenómeno. Los impactos sobre las poblaciones son múltiples, rupturas del tejido social, cambios abruptos en los proyectos de vida, sentidos permanentes de incertidumbre y otros impactos psicosociales, políticos, económicos y culturales, de orden individual y colectivo. Este desplazamiento forzado a inicios del siglo cobró dimensiones transfronterizas que hasta hoy se sostienen.

Hasta hace menos de una década en Colombia, poco y nada se hablaba de la migración internacional forzada. La crisis humanitaria declarada por los gobiernos de Ecuador y Venezuela por la llegada masiva de población colombiana en busca de protección internacional, en medio de la implementación del Plan Colombia y la ruptura de relaciones diplomáticas con los gobiernos vecinos en 2008, evidenció su dimensión y magnitud.

A nivel regional Colombia se constituyó en el principal expulsor intra y extra regional de población por razones de violencia sociopolítica, figurando a partir de 2005 entre los principales países de origen de población con necesidades de protección internacional ${ }^{26}$. En este marco, se empezó a hablar de población colombiana refugiada y víctimas en el exterior, generalmente para referirse a la que se encontraba en países de frontera. La instalación de la mesa de diálogos de La Habana, Cuba, visibilizó otro segmento poblacional que hace a la migración forzada internacional: el exilio.

\section{Acerca de los conceptos de víctima en el exterior, refugio y exilio}

Conceptos como refugiado/a, victima en el exterior y exiliado/a han empezado a ser usados en diferentes escenarios y por diversos actores de manera indistinta. Las discusiones surgidas al interior de la población migrada forzadamente, los efectos en las políticas públicas de reparación en el marco del conflicto armado y de los procesos transicionales posacuerdos de paz en el caso colombiano, ofrecen un acervo empírico para problematizar el concepto clásico de exilio, interrogar e interpelar a múltiples actores sobre sus dimensiones políticas, olvidos e impactos humanitarios.

Sin pretender minimizar los efectos de la pobreza estructural y la exclusión que impulsan movimientos migratorios en países del sur global, para efectos del desarrollo de este análisis, se considerará como migración forzada aquella que se causa en contextos de graves violaciones a los derechos humanos e infracciones al Derecho Internacional Humanitario ${ }^{27}$. Una de las preguntas que surge naturalmente es ¿cómo establecer quiénes son las víctimas de graves violaciones a los derechos humanos e infracciones al Derecho Internacional Humanitario? En tal sentido se propone abordar el concepto desde dos dimensiones: $i$ ) desde el derecho positivo y $i$ ) desde la politicidad.

25 Oficina del Alto Comisionado de las Naciones Unidas para los Refugiados, Tendencias Globales. Desplazamiento forzado en 2019, https://www.acnur.org/5eeaf5664.pdf

26 Oficina del Alto Comisionado de las Naciones Unidas para los Refugiados, Tendencias Globales. Desplazamiento forzado en 2017, https://www.acnur.org/5b2956a04.pdf

${ }^{27}$ Desde el derecho positivo se consideran violaciones flagrantes a los derechos humanos y a las libertades fundamentales e infracciones al Derecho Internacional Humanitario, en otras: el genocidio; la esclavitud o prácticas similares; las ejecuciones sumarias o extrajudiciales, la tortura y penas o tratos crueles, inhumanos o degradantes; la desaparición forzada; la detención arbitraria y prolongada; la deportación o desplazamiento forzoso de poblaciones; la discriminación sistemática, en particular por motivos de raza o sexo; la destrucción de poblados, la devastación injustificada de regiones apelando razones militares, el asesinato o malos tratos de prisioneros o muerte de rehenes. 


\title{
Aproximaciones y tensiones conceptuales desde el derecho positivo
}

La Asamblea General de las Naciones Unidas, en su resolución 60/147 de diciembre 16 de 2005, estableció los principios y directrices básicos sobre el derecho de las víctimas de violaciones manifiestas de las normas internacionales de Derechos Humanos y de graves vulneraciones al Derecho Internacional Humanitario, para interponer recursos y obtener reparaciones. El punto $\mathrm{V}$ del documento establece que:

\begin{abstract}
...se entenderá por víctima a toda persona que haya sufrido daños, individual o colectivamente, incluidas lesiones físicas o mentales, sufrimiento emocional, pérdidas económicas o menoscabo sustancial de sus derechos fundamentales, como consecuencia de acciones u omisiones que constituyan una violación manifiesta de las normas internacionales de derechos humanos o una violación grave del derecho internacional humanitario. Cuando corresponda, y en conformidad con el derecho interno, el término «víctima» también comprenderá a la familia inmediata o las personas a cargo de la víctima directa y a las personas que hayan sufrido daños al intervenir para prestar asistencia a víctimas en peligro o para impedir la victimización ${ }^{28}$.
\end{abstract}

Esta resolución determina un marco obligado de interpretación y referencia, pero al no tener un carácter vinculante requiere que una legislación propia de orden nacional la aplique y reglamente ${ }^{29}$.

En 2011, tras años de movilización de víctimas, organizaciones de víctimas y defensoras de derechos humanos, el gobierno colombiano dictó medidas para la atención, asistencia y reparación integral a las víctimas de graves violaciones a los derechos humanos en el marco del conflicto interno, a través de la Ley de Víctimas y Restitución de Tierras (Ley 1448/2011). Sin embargo, el concepto de víctima que contempla esta ley imprime recortes temporales y de concepto a las definiciones establecidas por la tradición del derecho internacional de los derechos humanos.

La exclusión temporal reconoce la condición de víctimas solo a quienes hayan sufrido daños por hechos vulneratorios ocurridos con posterioridad a 1985. Las restricciones por concepto excluyen del reconocimiento a los «miembros de grupos armados ilegales» para quienes desconoce la vigencia del Derecho Internacional Humanitario ${ }^{30}$. Igualmente, se desconoce como víctimas a quienes hayan sufrido un daño en sus derechos como consecuencia de actos de delincuencia común, restricción problemática al diversificarse los

\footnotetext{
${ }^{28}$ Oficina del Alto Comisionado de las Naciones para los Derechos Humanos, Principios y directrices básicos sobre el derecho de las víctimas de violaciones manifiestas de las normas internacionales de derechos humanos $y$ de violaciones graves del derecho internacional humanitario a interponer recursos y obtener reparaciones (Asamblea General de Naciones Unidas, 16 de diciembre de 2005).

${ }^{29}$ Diana Ortiz y Mauricio Viloria, Retorno voluntario, digno y con garantías. Reflexiones de la población refugiada, exiliada y víctima del conflicto armado colombiano en América Latina y el Caribe (Buenos Aires: REVICPAZ-LAC, 2018).

${ }^{30}$ El parágrafo c del artículo 3 de la Ley de Víctimas y Restitución de Tierras establece: «Parágrafo $2^{\circ}$. Los miembros de los grupos armados organizados al margen de la ley no serán considerados víctimas, salvo en los casos en los que los niños, niñas o adolescentes hubieren sido desvinculados del grupo armado organizado al margen de la ley siendo menores de edad. Para los efectos de la presente Ley, el o la cónyuge, compañero o compañera permanente, o los parientes de los miembros de grupos armados organizados al margen de la ley serán considerados como víctimas directas por el daño sufrido en sus derechos en los términos del presente artículo, pero no como víctimas indirectas por el daño sufrido por los miembros de dichos grupos» (Ley 1448/2011: 10). Ley de Víctimas y Restitución de Tierras, http://www.centrodememoriahistorica.gov.co/descargas/ley victimas/ley_victimas_completa_web.pdf
} 
actores armados en los territorios luego de los acuerdos entre el gobierno y los paramilitares $^{31}$.

Estás limitaciones del concepto deberían ser resueltas en el ajuste normativo a la Ley 1448/2011, conforme a los compromisos adquiridos en el punto cinco del Acuerdo Final para la Terminación del Conflicto y la Construcción de una Paz Estable y Duradera, firmado en noviembre de 2016 por las Fuerzas Armadas revolucionarias de Colombia-Ejército del Pueblo, FARC-EP y el Estado colombiano. El ajuste supondría, además: la realización de eventos amplios de participación previos, que consultarán a las víctimas, sus organizaciones y otros actores relevantes sobre los componentes de la reforma, el fortalecimiento de los mecanismos de reparación colectiva y el diseño de políticas públicas para refugiados, exiliados y víctimas en el exterior. Pese a que estos aspectos figuraban en las prioridades de implementación, no se incluyeron en el fast track ni en las agendas legislativas posteriores.

El Registro Único de Víctimas, a fines de septiembre de 2020, reportó el reconocimiento de la condición de víctimas a 25.720 personas que rindieron su declaración en el exterior. En contra parte, el informe de tendencias globales 2019 de ACNUR determina que 265.004 personas colombianas que están refugiadas en el mundo son solicitantes o están en condición similar, esto significa personas que están fuera de su país de origen con iguales riesgos de protección, pero con distinta condición de reconocimiento. Los datos anteriores dan cuenta de que el Registro Único de Víctimas reconoce como víctima a menos del $10 \%$ de esta población.

El refugio es un mecanismo jurídico de protección humanitario definido por la Convención del Estatuto de los Refugiados de 1951 y por el Protocolo sobre el Estatuto de los Refugiados del 1967, que se otorga a personas con temores fundados de persecución por razones políticas, étnicas, religiosas, pertenencia a un grupo social o nacional y que por causa de estos temores se encuentra fuera de su país de origen, no pudiendo o queriendo regresar a él ni acogerse a su protección. El concepto fue ampliado regionalmente por la Declaración de Cartagena en 1984, e incluyó situaciones de violencia generalizada y graves violaciones a los derechos humanos.

El estatus de refugio es otorgado por los Estados de acogida previa evaluación de la solicitud presentada por la persona peticionante, según las normativas nacionales vigentes. El principio fundamental del refugio es la no devolución mientras se mantengan las condiciones objetivas y subjetivas de riesgo.

Según las cifras de ACNUR, cerca del $80 \%$ de las personas colombianas con necesidades de protección internacional se encuentran en la región; donde si bien predominan buenas prácticas como la no detención durante el procedimiento, las respuestas de asistencia humanitaria son transitorias y la resolución de los trámites de otorgamiento de la condición extremadamente demorados. Así, muchas poblaciones vulneradas por el conflicto son luego vulnerables por exclusión en los lugares de llegada.

\section{Resignificaciones conceptuales e identitarias desde la politicidad}

Según plantea Surraco $^{32}$, el lenguaje del derecho internacional humanitario tiende a dar opacidad a las razones sociopolíticas concretas por las que determinado(s) grupo(s) de

\footnotetext{
${ }^{31}$ En 1995 el Gobierno colombiano promulgó la Ley 975 de 2005 para dar lugar a la desmovilización de grupos paramilitares conocida como Ley de Justicia y Paz.

${ }^{32}$ Leonardo Surraco, «Políticas públicas reparatorias dirigidas al universo de víctimas de graves violaciones a los derechos humanos y efectos de las prácticas sociales genocidas. - El caso de los hijos de desaparecidos y asesinados por el terrorismo de Estado en Argentina y el posicionamiento del Cdh—» (Tesis de maestría,
} 
personas se constituyeron en blanco del poder y la represión estatal. Esto genera resistencias en segmentos poblacionales politizados que perciben el concepto de víctima, como un lugar pasivo de «cuerpo dócil frente a los dispositivos de aniquilamiento» ${ }^{33}$, desprovisto de las motivaciones políticas que le dieron sentido a la acción del sujeto.

Abordar el concepto de víctimas desde la politicidad ofrece un marco de análisis que aborda las agencias y cambios, que en distintas escalas se dan a partir de sus acciones y demandas. En el caso colombiano, el punto cinco de la agenda de diálogos y posterior acuerdo de paz, dio cursó a una problematización del concepto exilio en medio de disputas por su inscripción - $\mathrm{O}$ no- en el universo de víctimas en el exterior definido por la Ley 1448/2011. Las tensiones entorno a la promulgación de otras categorías de víctimas en el exterior, durante los procesos de relacionamiento con las instituciones pre y posacuerdos de paz encargadas del reconocimiento-clasificación, pusieron de manifiesto la dimensión de politicidad $^{34}$ del concepto de víctimas como quedó plasmado en el punto 5.1.3.5 del Acuerdo Final:

En cuanto al gran número de víctimas que debieron abandonar el país como consecuencia de diferentes violaciones a los derechos humanos e infracciones al DIH con ocasión del conflicto, el Gobierno Nacional, en desarrollo de este Acuerdo, fortalecerá el programa de reconocimiento y reparación de víctimas en el exterior, incluyendo refugiados y exiliados victimizados con ocasión del conflicto (Acuerdo Final, 2016:183)

Es así como el concepto de víctimas en Colombia se constituyó, por acción de la organización y el debate público, en una categoría política; a diferencia de otros procesos donde su centralidad está definida por un concepto jurídico, que supone a la víctima como sujeto tutelado más que político y adjudica al poder judicial su representación. Llegar a este resultado significó una amplia movilización, en medio de la diversidad de acciones y prácticas políticas. El exilio disputó en espacios de poder público representaciones y sentidos entorno al concepto de víctimas en el exterior.

El exilio más allá de un contexto histórico y político específico es considerado como una pena o castigo, que puede estar regida o no desde el ámbito jurídico y recae sobre quienes son señalados/as culpables de delitos políticos. Tiene, por lo tanto, como fin excluir políticamente a las personas opositoras ${ }^{35}$.

En el amplio universo de población colombiana con necesidades de protección internacional confluyen entonces, tanto las víctimas definidas desde la concepción del derecho positivo como desde la politicidad, independientemente de que hayan recurrido o no a la figura de refugio.

Universidad Nacional de San Martín, 2013), http://www.unsam.edu.ar/ciep/wpcontent/uploads/2013/06/Surraco_Leonardo_Tesis1.pdf

${ }^{33}$ Surraco, L. «Políticas públicas reparatorias dirigidas al universo de víctimas de graves violaciones a los derechos humanos y efectos de las prácticas sociales genocidas. - El caso de los hijos de desaparecidos y asesinados por el terrorismo de Estado en Argentina y el posicionamiento del Cdh—», 14.

${ }^{34}$ Mary Douglas, Cómo piensan las instituciones (Madrid: Alianza, 1996). Pierre Bourdieu, Intelectuales, Política y Poder (Buenos Aires: Editorial Universitaria de Buenos Aires, 2011).

${ }^{35}$ Silvina Jensen. «¿Por qué sigue siendo políticamente incorrecto hablar de exilio? La dificultosa inscripción del exilio en las memorias sobre el pasado reciente argentino (1983-2007)», Revista Digital de la Escuela de Historia, n. ${ }^{\circ} 1$ (2008):131-148. Luis Roniger, Destierro y exilio en América Latina. Nuevos estudios y avances teóricos (Buenos Aires: Editorial de la Universidad de Buenos Aires, 2014). Mariela Ávila, «El exilio en el Cono Sur: acercamientos a un problema siempre vigente». HYBRIS. Revista de Filosofía 10, Especial. Dossier: Pensar en Chile 1973-1990 (2019): 155-179. 
Exilio y refugio son claramente clasificables como fenómenos de migración forzada, categoría menos precisa para explicar los movimientos de aquellas víctimas del conflicto que no vinculan directamente su migración con los hechos victimizantes. En tales casos, puede atribuirse un cierto nivel de autonomía para decidir permanecer en el país o marcharse. Es el caso, por ejemplo, de aquellas personas que migraron muchos años después de los daños sufridos en el marco de la violencia sociopolítica. Sin embargo, en diversos espacios de diálogo con víctimas en el exterior (directas e indirectas), suelen manifestarse expresiones como «darle una oportunidad a la vida», «sobreponerse al miedo», «desencanto con el país», «la violencia cansa», asociadas a los motivos para migrar.

La imposibilidad de reconstruir proyectos de vida da cuenta de un daño no cesado y de algún modo del fracaso de una política de reparación que no restituye derechos. En ocasiones el mayor deterioro de las condiciones de vida es el resultado de la implementación de planes de desarrollo gubernamental de gran escala que imponen cierta trashumancia marcada por procesos continuos de «desplazamiento y reasentamiento», que revisten irrefutable nivel de coerción directa e indirecta sobre las personas y poblaciones ${ }^{36}$, aunque no siempre resulte evidente su relación con las dinámicas del conflicto armado.

\section{El derecho a la verdad del exilio}

La Comisión Interamericana de Derechos Humanos estableció en 1999 que el derecho a la verdad tiene dos dimensiones, la individual y la colectiva, que a su vez constituyen dos ámbitos: el público y el privado.

El derecho a la verdad es un derecho de carácter colectivo que permite a la sociedad tener acceso a información esencial para el desarrollo de los sistemas democráticos y a la vez un derecho particular para los familiares de las víctimas, que permite una forma de reparación ${ }^{37}$.

Desde 1974 hasta 2007 se crearon comisiones de la verdad en 28 países, más de la mitad fueron en la última década. Para el caso de América Latina y el Caribe se cuentan trece. Dos países han reinstalado Comisiones, una década después de la culminación del mandato de la primera ${ }^{38}$.

Pocas Comisiones de la Verdad han abordado la migración forzada internacional entre las graves violaciones de los derechos humanos y el derecho internacional humanitario, entre ellas, se encuentran la de Liberia y la del Paraguay.

36 C. McDowell, «Development-Induced Displacement», The Courier Africa-Caribbean-Pacific/European Community, n. ${ }^{\circ} 150$ (1995).

${ }^{37}$ Comisión Interamericana de Derechos Humanos, 8 informe $N^{o} 136 / 99$, caso 10.488, Ignacio Ellacuría, S. J. y otros (El Salvador, 22 de diciembre de 1999), párr. 224.

${ }^{38}$ Amnistía Internacional, Verdad, justicia y reparación. Creación de una comisión de la verdad efectiva (Reino Unido, 2007). La Comisión Nacional de Investigación de Desaparecidos Forzados de Bolivia en 1982 fue la primera en América Latina y el Caribe; seguida de la Comisión Nacional sobre la Desaparición de Personas de Argentina (1983); Comisión Investigadora sobre la Situación de Personas Desaparecidas y Hechos que la Motivaron (1985) de Uruguay, y quince años después se creó; las Comisiones Nacional de Verdad y Reconciliación (1990) de Chile; Comisión de la Verdad de El Salvador (1992); Comisión Nacional de la Verdad y la Justicia de Panamá (1995); Comisión «Verdad y Justicia» de Ecuador (1996); Comisión para el Esclarecimiento Histórico de las Violaciones a los Derechos Humanos y los Hechos de Violencia que han Causado Sufrimientos a la Población Guatemalteca (1997); Comisión de la Verdad y Reconciliación de Perú (2000); Comisión de la Verdad de Haití (2001) y Comisión de la Verdad y la Justicia de Paraguay (2003). Países como Uruguay y Chile crearon varios años después dos comisiones más: la Comisión para la Paz de Uruguay (2000) y la Comisión Nacional sobre Prisión Política y Tortura de Chile (2003). 
Entre 1979 y 2003, Liberia vivió una dictadura militar y dos guerras civiles que llevaron al exilio a cerca de tres millones de personas. La Comisión de la Verdad y Reconciliación tomó más de mil quinientos testimonios distribuidos en Reino Unido, Estados Unidos y Ghana y llevó a cabo algunas audiencias públicas ${ }^{39}$.

Paraguay vivió bajo la dictadura militar del general Alfredo Stroessner entre 1954 y 1989. Quince años después de la vuelta a la democracia se constituyó la Comisión de la Verdad y Justicia, CVJ, que inició su mandato en 2004 y presentó las conclusiones y recomendaciones en 2008. Entre las acciones que desplegó la CVJ en el exilio, se encuentran dos audiencias públicas e instalación de una Unidad de Toma de Testimonios que funcionó entre 2006 y 2008, en las provincias fronterizas con Argentina: Misiones, Corrientes y Formosa. La primera Audiencia Pública se llevó a cabo en la ciudad de Buenos Aires, considerada capital del exilio paraguayo, el 30 de mayo de 2006, con sede en el Congreso de la Nación Argentina. La segunda audiencia se realizó el 19 de octubre de 2007 con el exilio fronterizo, en la ciudad de Posadas, provincia Misiones.

El exilio fue considerado dentro de las principales violaciones cometidas por el régimen stronista, dada su masividad, larga duración y la correlación con otras violaciones. En sus conclusiones la CVJ estableció que el exilio fue consecuencia de actos arbitrarios cometidos por el Estado, como la privación de la libertad contra quienes acusó de «comunistas», las restricciones al derecho de libre residencia y libre circulación y la inseguridad y falta de acceso a la justicia. La continuidad y sistematicidad de estas vulneraciones obligaron a muchas personas a cruzar las fronteras nacionales y permanecer contra su voluntad en territorio extranjero.

En su abordaje del exilio como violación a los derechos humanos cometidas por la dictadura, la Comisión documentó 3470 testimonios de personas exiliadas directas y estimó una migración forzada de 1,4 millones y, sin dejar de advertir un «enorme subregistro», aclaro que:

Las aproximaciones que se han realizado en el pasado a esta problemática mezclan el exilio, refugio o asilo político con la situación de los migrantes económicos. La CVJ no desconoce que las migraciones económicas tienen su origen en circunstancias de violencia estructural, pero, teniendo en cuenta el mandato de la Comisión, la cifra expandida bajo la denominación de exilio intenta señalar una aproximación solamente frente a las personas que fueron expulsadas u obligadas a abandonar el Paraguay por razones políticas ${ }^{40}$.

En Colombia, el modelo de justicia transicional establecido por el Acuerdo Final dio lugar a la creación del Sistema Integral de Verdad, Justicia, Reparación y No Repetición, SIVJRNR. Un sistema que integra mecanismos autónomos judiciales y extrajudiciales como la Jurisdicción Especial para la Paz, JEP; la Comisión para el Esclarecimiento de la Verdad, la Convivencia y la No Repetición, CEV y la Unidad de Búsqueda de Personas dadas por Desaparecidas, UBPD.

El Decreto 588 del 5 de abril de 2017 determinó las disposiciones generales, los criterios orientadores, mandato, funciones, atribuciones y metodología, entre otros aspectos,

\footnotetext{
${ }^{39}$ Ursula Bairrogia y Enán Arrieta, «¿Cómo reconocer el exilio colombiano? Hacia una justicia transicional transnacional», en Entre la guerra y la paz: los lugares de la diáspora colombiana, ed. por Ángela Iranzo y Edson Wooldy (Bogotá: Universidad de los Andes, 2018), 75-96.

${ }^{40}$ Comisión de Verdad y Justicia del Paraguay, CVJ. Conclusiones y recomendaciones del informe final de la Comisión de Verdad y Justicia del Paraguay (Asunción, 28 de agosto de 2008), numeral 67.
} 
de la Comisión para el Esclarecimiento de la Verdad. En su mandato se encuentra el aportar elementos para el esclarecimiento, con enfoque diferencial, del impacto social y humano de las graves violaciones a los derechos humanos, entre estas las vividas por «las personas desplazadas y exiliadas o víctimas del conflicto que se encuentren en el exterior» ${ }^{41}$. Así como el impacto del conflicto en «el ejercicio de la política y el funcionamiento de la democracia en su conjunto, incluyendo a los partidos y movimientos políticos y sociales, en particular los de oposición» ${ }^{42}$ y sobre «quienes participaron directamente en él como combatientes y sobre sus familias y entornos» ${ }^{43}$.

Para dar cumplimiento a su mandato y objetivos en cuanto al exilio se refiere, la Comisión definió un enfoque extraterritorial ${ }^{44}$ para trabajar con «la Colombia fuera de Colombia» en palabras del Comisionado responsable Carlos Martín Beristain.

El despliegue extraterritorial de la Comisión durante sus dos primeros años (20182019) fue posible gracias a la articulación con redes de organizaciones de las personas exiliadas colombianas en Europa y América. A través de las cuales pudo impulsar su trabajo en 23 países y organizar cinco territorios denominados nodos: Europa, Norteamérica, Centroamérica, Países Andinos y Suramérica.

La visibilidad de estas redes, que sirvieron de base a la Comisión, fue impulsada entre 2015 y 2018 por el proyecto Agenda Exilio, del Centro Nacional de Memoria Histórica, $\mathrm{CNMH}$, creado por la Ley de Víctimas y Restitución de Tierras. Este proyecto desarrolló tres ejes de trabajo: investigación, participación de víctimas en el exterior y retornadas y apoyo a iniciativas de memoria ${ }^{45}$.

El conflicto armado colombiano no ha respetado las fronteras. Miles de personas han tenido que salir del país, refugiándose de diversas condiciones de violencia. El Estado tiene una deuda histórica con la población exiliada que se expresa mediante la invisibilización de sus realidades y experiencias asociadas a los impactos del conflicto armado ${ }^{46}$.

A un año de terminar su mandato, la Comisión cuenta con el apoyo de diversos actores en los países de acogida, pocos nodos son coordinados directamente por la población colombiana migrada forzadamente, aunque en todos hay una participación significativa de ella, no solo en lo referido a temas de esclarecimiento.

\footnotetext{
${ }^{41}$ Presidencia de la Republica, Decreto 588 del 5 de abril de 2017. Por el cual se organiza la Comisión para el Esclarecimiento de la Verdad, la Convivencia y la No Repetición, tít. III, art. 11, n. ${ }^{\circ}$ 3, http://es.presidencia.gov.co/normativa/normativa/DECRETO\%20588\%20DEL\%2005\%20DE\%20ABRIL\%2 0DE\%202017.pdf

${ }^{42}$ Presidencia de la Republica, Decreto 588 del 5 de abril de 2017, tít. III, art. 11 , n. ${ }^{\circ} 4$.

43 Presidencia de la Republica, Decreto 588 del 5 de abril de 2017, tít. III, art. 11, n. $^{\circ} 5$.

${ }^{44}$ La Comisión para el Esclarecimiento definió la constitución de 11 territorios para su despliegue: Antioquia y Eje Cafetero, Caribe Insular, Pacífico, Territorios étnicos, Centroandina, Surandina, Amazonía, Orinoquía, Bogotá y Soacha, Nororiente, Magdalena medio, Internacional.

45 Entre los principales resultados obtenidos desde las distintas iniciativas impulsadas por el CNMH, primordialmente con población exiliada en Europa y víctima del conflicto en países de frontera, se encuentran la serie audiovisual de «Voces del Exilio» y la publicación «Exilio colombiano Huellas del conflicto armado más allá de las fronteras» resultado de la investigación en países fronterizos.

${ }^{46}$ Centro Nacional de Memoria Histórica, «ACNUR y CNMH, una alianza por el exilio», 3 de agosto de 2016, acceso el 23 de noviembre de 2020, https://centrodememoriahistorica.gov.co/acnur-y-cnmh-una-alianza-porel-exilio/
} 
En aquellos nodos en los que se destaca la participación organizada de la población exiliada es posible identificar una relación previa con el amplio universo de la migración forzada. En alianza con organizaciones dedicadas a la defensa de los derechos de migrantes y refugiados se facilitaron procesos de asesoramiento y apoyo a las víctimas y refugiados para acceder al Registro Único de Víctimas y hacer seguimiento de sus procesos de reparación desde el exterior, acceder a la regularidad migratoria y solicitar refugio. A partir de atender demandas específicas de este tipo, lograron construir redes vinculares que posibilitaron círculos de confianza, no solo con la población, sino también con organizaciones e instituciones de los países de acogida, que han permitido avanzar en el despliegue extraterritorial.

El primer reto que tuvo que enfrentar la Comisión para el Esclarecimiento de la Verdad fue ganar la confianza de la población exiliada. La autonomía de la que gozan las tres instancias que conforman el Sistema Integral de Verdad, Justicia, Reparación y No Repetición y la participación de personas reconocidas defensoras de derechos humanos, le permitió lidiar con el desprestigio del que goza la institucionalidad colombiana.

El segundo reto, fue construir el proceso en tiempo récord con recursos limitados para su funcionamiento, apoyándose en el trabajo voluntario de cientos de personas en el exterior. Sigue siendo un desafío desarrollar una metodología que permita involucrar efectivamente a la población, en todas las etapas del proceso.

El trabajo hasta ahora desplegado por la Comisión para el Esclarecimiento de la Verdad en el exterior ha posibilitado espacios de encuentro y reconocimiento entre el propio exilio, eso es fuera de Colombia. Poco se ha logrado impulsar escenarios de encuentro y reconocimiento con el país que permanece dentro del territorio, pues los impactos no solo son sufridos por quienes se ven obligados a salir del país sino también, por quienes permanecen: familiares, amigos, compañeros de militancias, procesos colectivos y comunitarios. Esto implica la promoción de espacios de reconocimiento y reparación multisituados, dirigidos tanto a quienes partieron como a quienes permanecieron.

Como se señaló anteriormente, en medio de los avances del enfoque extraterritorial del Sistema, se torna un poco difusa la categoría de exilio al usarse para referirse indistintamente a víctimas en el exterior, refugiados/as y exiliados/as. A partir de las categorías de migración política y de exilio propuestas por Franco y Bernaldo ${ }^{47}$, se sugiere establecer la migración forzada para construir el objeto y el exilio como categoría utilizada por los propios actores para otorgar sentido político a los hechos sufridos.

La experiencia desarrollada con la Comisión para el Esclarecimiento de la Verdad en el campo testimonial ha puesto en evidencia que se hace necesario considerar «la percepción que tienen los actores de su propia experiencia, y que a la vez condiciona la percepción que de ellos tienen tanto la sociedad de origen como la de acogida ${ }^{48}$.

Testimonios cargados de narrativas atravesadas por salidas repentinas, persecuciones y perspectivas de retorno a partir de los cambios esperados en la situación política se vislumbra con mayor dimensión en el colectivo conformado por el exilio, más que en otros que también hacen parte de la migración forzada. La demanda por el reconocimiento del

\footnotetext{
${ }^{47}$ Marina Franco y Pilar Bernaldo, «Cuando el sujeto deviene objeto: la construcción del exilio argentino en Francia. Represión y Destierro. Itinerarios del Exilio Argentino», en Itinerarios del Exilio Argentino, coord. por P. Yankelivich (Buenos Aires: Ed. Al Margen, 2004), 17-47.

${ }_{48}$ Franco y Bernaldo, «Cuando el sujeto deviene objeto: la construcción del exilio argentino en Francia. Represión y Destierro. Itinerarios del Exilio Argentino», 19.
} 
exilio como práctica represiva generada sistemáticamente por el Estado colombiano, para excluir políticamente a diversos sectores de oposición, es una muestra de construcción de sentido político en torno al acto testimonial.

En las narrativas del exilio sobresalen aspectos relacionados con el espacio conformado por múltiples cataduras políticas que hacían a la vida cotidianidad previa al evento migratorio. Acciones y discursos sobre los que operaron los factores de expulsión, y que las personas exiliadas resignifican y reconfiguran una vez afuera. Ellos/as pueden posicionarse y construirse como un actor político en el que intervienen experiencia y trayectorias individuales y colectivas, previas y adquiridas en los nuevos marcos de acción que ofrecen los países de acogida.

Entre los derroteros de la Comisión está dar cuenta de la inconveniencia analítica de separar el exilio de las experiencias y trayectorias previas de aquellas personas a quienes la violencia política en Colombia expulsó. Para esclarecer su sistematicidad, motivos, impactos y distintas formas de afrontamiento debe también considerarse la situación política de los países de acogida y el contexto internacional. El exilio analizado como «una pena que se impone por motivos políticos declarados, y que expulsa a ciertos sujetos de su comunidad y su territorio» ${ }^{49}$.

En un contexto donde la violencia sociopolítica se acrecienta, el llamado a la No Repetición vuelve a ser sustituido por un pedido al cese del horror, para detener el derramamiento de sangre. Sin embargo, aún es posible que la Comisión para el Esclarecimiento de la Verdad, con el apoyo internacional y el respaldo de la ciudadanía, contribuya a la desnaturalización social de la violencia y convoque al conjunto de la sociedad a buscar caminos alternativos para construirnos como nación.

Grandes desafíos enfrentan esa Colombia que le apuesta a la paz en materia de memoria, verdad y justicia, entre ellos: desandar el maniqueísmo polarizado de la sociedad, romper con la naturalización de la violencia política para lograr dimensionar los horrores de la guerra y sus impactos y avanzar en la reestructuración de unas Fuerzas Armadas que, formadas bajo la doctrina de la seguridad nacional, han dado tratamiento de enemigo interno a los conflictos sociales.

Sacar de la esfera privada los impactos de las ausencias que ha dejado y sigue dejando la violencia política para ponerlos en la esfera pública posibilitará aproximarse a la no repetición como deber de Estado y como derecho de la sociedad. El exilio es uno de los impactos más silenciosos de la violencia política, con su enunciación y nuevas agencias ha logrado constituirse como un actor político que se une a los reclamos por el derecho a la memoria, a la verdad y a la justicia. Le queda al tiempo establecer si la Comisión para el Esclarecimiento de la Verdad, la Convivencia y la No Repetición responderá a esas expectativas y si la sociedad podrá avanzar en el reconocimiento de los daños que individual y colectivamente ha causado el exilio.

El exilio implica rupturas en las subjetividades que componen el tejido social, pero su afrontamiento también ofrece aprendizajes que pueden aportar en la construcción de nuevos espacios y territorios para rehabitar el país.

\section{A modo de conclusión}

\footnotetext{
${ }^{49}$ Mariela, Ávila, «El exilio en el Cono Sur: acercamientos a un problema siempre vigente», HYBRIS. Revista de Filosofía 10, n. ${ }^{\circ}$ Especial. Dossier: Pensar en Chile 1973-1990 (2019): 156.
} 
La migración forzada internacional de los últimos cuarenta años, de manera particular la registrada en este siglo, presenta características específicas que la diferencian de otros procesos de emigración anteriores y permite deconstruir imaginarios que disocian los flujos migratorios de los impactos sociales, políticos y culturales asociados a la violencia sociopolítica. Enfoques que tradicionalmente invisibilizan los impactos del conflicto en la migración internacional y centran sus marcos generales en la emigración por motivos económicos o académicos.

El exilio no solo se inscribe dentro de los flujos de las distintas oleadas emigratorias, sino que también da cuenta de la dimensión política que empieza a evidenciarse en la década de los ochenta, como consecuencia directa de las prácticas represivas, estatales y paraestatales, implementadas contra diversos sectores opositores a las políticas de estado.

En los últimos veinte años del siglo XX la represión se centró en las figuras alternativas más representativas, que entraron en la pugna con el poder tradicional en las elecciones a órganos de gobierno nacional y local. En el nuevo siglo, la represión se agudizó contra los movimientos sociales territoriales y sus espacios de gobernanza, especialmente en territorios fronterizos con importantes recursos naturales y presencia histórica de las insurgencias. Se diversificaron y ampliaron, entonces, los perfiles de la migración forzada.

La instalación de los diálogos y firma del último acuerdo de paz, y la posterior implementación de la Comisión para el Esclarecimiento de la Verdad, la Convivencia y la No Repetición, posibilitaron que las personas exiliadas se posicionaran como nuevos actores políticos en el plano internacional, con agendas y agencias propias y heterogéneas. En algunos casos, independientes de las plataformas político-partidarias o de inscripciones ideológicas previas.

Este nuevo actor, que reclama esclarecimiento, reconocimiento, medidas de reparación y no repetición, enfrenta tensiones entorno a su reconocimiento como víctima del conflicto y al derecho a la participación en la definición de políticas de memoria, verdad y justicia. Tensiones que pueden analizarse desde la perspectiva jurídica que ofrece el derecho positivo y desde la politicidad.

La Comisión para el Esclarecimiento de la Verdad, la Convivencia y la No Repetición enfrenta varios desafíos en cuanto al exilio se refiere. Es importante que se precisen las categorías de análisis, de modo que no resulten obliterados los móviles represivos y políticos del exilio ni se invisibilicen otras poblaciones forzadas a la migración internacional. Reconocer el exilio como práctica represiva sistemática que busca la exclusión política implica dar relevancia a la dimensión política en la que se definen los propios actores y desde allí sus acciones y prácticas. El reconocimiento del exilio y de la migración forzada internacional es una deuda que el Estado debe asumir de cara a la sociedad en su conjunto.

Las conclusiones y recomendaciones sobre el exilio de la Comisión de Verdad y Justicia de Paraguay pueden resultar útiles para Colombia. Asimismo, el exilio colombiano podrá aportar una gran experiencia, adquirida en el proceso del despliegue extraterritorial de la Comisión para el Esclarecimiento de la Verdad, para el desarrollo de escenarios académicos, organizativos y de incidencia, entorno al diseño, implementación y seguimiento de políticas públicas sobre memoria, verdad y justicia, no solo en Colombia, sino en toda la región.

\section{Referencias}


Amnistía Internacional. Verdad, justicia y reparación. Creación de una comisión de la verdad efectiva. Reino Unido, 2007.

Archila, Mauricio. «El paro cívico nacional del 14 de septiembre de 1977 . Un ejercicio de memoria colectiva». Revista de Economía Institucional 18, n. ${ }^{\circ} 35$ (2016): 313-318. doi: https://doi.org/10.18601/01245996.v18n35.18

Ávila, Mariela. «El exilio en el Cono Sur: acercamientos a un problema siempre vigente». HYBRIS. Revista de Filosofía 10, n. ${ }^{\circ}$ Especial. Dossier: Pensar en Chile 1973-1990 (2019): 155-179.

Bairrogia, Ursula y Enán Arrieta. «¿Cómo reconocer el exilio colombiano? Hacia una justicia transicional transnacional». En Entre la guerra y la paz: los lugares de la diáspora colombiana, editado por Ángela Iranzo y Edson Wooldy, 75-96. Bogotá: Universidad de los Andes, 2018.

Bourdieu, Pierre. Intelectuales, Política y Poder. Buenos Aires: Editorial Universitaria de Buenos Aires, 2011.

Cardona, Ramiro. Las migraciones internas. Bogotá: Editorial Andes, 1968.

Centro Nacional de Memoria Histórica. Paramilitarismo. Balance de la contribución del CNMH al esclarecimiento histórico. Bogotá, CNMH, 2018a.

. Todo pasó frente a nuestros ojos. El genocidio de la Unión Patriótica 1984-2002. Bogotá, CNMH, 2018b.

«ACNUR y CNMH, una alianza por el exilio». Acceso el 23 de noviembre de 2020, https://centrodememoriahistorica.gov.co/acnur-y-cnmh-una-alianza-por-el-exilio/

Comisión Interamericana de Derechos Humanos. 8 informe $N^{o}$ 136/99, caso 10.488, Ignacio Ellacuría, S. J. y otros. El Salvador, 22 de diciembre de 1999, párr. 224.

Comisión de Verdad y Justicia del Paraguay, CVJ. Conclusiones y recomendaciones del informe final de la Comisión de Verdad y Justicia del Paraguay. Asunción, 28 de agosto de 2008 .

Departamento Administrativo Nacional de Estadística. Anuario Estadístico 2002-2003. Movimientos migratorios internacionales de Colombia. Bogotá, 2004.

«Estudios Postcensales. Estimación de la migración 1975-2005». Bogotá: DANE, 2008. Acceso el 23 de noviembre de 2020. https://www.dane.gov.co/files/investigaciones/poblacion/migraciones/doc_est_mig 1973_2005.pdf

. «Censo Nacional de Población y Vivienda 2018». Acceso el 23 de noviembre de 2020. https://www.dane.gov.co/index.php/estadisticas-por-tema/demografia-ypoblacion/censo-nacional-de-poblacion-y-vivenda-2018/herramientas 
. «Anuario estadístico de movimientos internacionales. Información 2018». Acceso el 23 de noviembre de 2020. https://www.dane.gov.co/index.php/estadisticas-portema/demografia-y-poblacion/movilidad-y-migracion/anuarios-estadisticos-de$\underline{\text { movimientos-internacionales }}$

Departamento de Extranjería y Migraciones de Chile. «Estadísticas Migraciones». Acceso 20 de junio de 2020 .

https://www.extranjeria.gob.cl/estadisticas-migratorias/

Dirección Nacional de Migraciones de Argentina. «Estadísticas Migraciones». Acceso del 20 de junio de 2020. https://www.argentina.gob.ar/interior/migraciones/estadisticas

Dirección Nacional de Migraciones de Uruguay. Acceso 20 de junio de 2020. https://migracion.minterior.gub.uy/index.php/estadisticas

Douglas, Mary. Cómo piensan las instituciones. Madrid: Alianza, 1996.

Franco, Marina y Bernaldo, Pilar. «Cuando el sujeto deviene objeto: la construcción del exilio argentino en Francia. Represión y Destierro. Itinerarios del Exilio Argentino». En Itinerarios del Exilio Argentino, coordinado por P. Yankelivich, 17-47. Buenos Aires: Ed. Al Margen, 2004.

Hugo, Graeme y Chan Bun Kwok. «Conceptualizing and Defining Refugee and Forced Migrations in Asia». Southeast Asian Journal of Social Science 18, n. 1 (1990), 1942.

Jensen, Silvina. «¿Por qué sigue siendo políticamente incorrecto hablar de exilio? La dificultosa inscripción del exilio en las memorias sobre el pasado reciente argentino (1983-2007)». Revista Digital de la Escuela de Historia, $\mathrm{n}^{\circ} 1$ (2008):131-148.

Mármora, Lelio. «El Desarrollo de la Política de Migraciones Laborales en Colombia». En Migraciones Laborales 1, 43-74. Bogotá, D.C.: Senalde-Ministerio de Trabajo y Seguridad Social de Colombia, Proyecto PNUD-OIT Migraciones Laborales, 1976.

McDowell, C. «Development-Induced Displacement". The Courier Africa-CaribbeanPacific/European Community, n. ${ }^{\circ} 150$ (1995): 56-57.

Mejía, William. «Colombia y las migraciones internacionales. Evolución reciente y panorama actual a partir de las cifras». Revista Interdisciplinar da Mobilidade Humana XX, n. 39 (2012): 185-210.

«Casi dos siglos de migración colombiana a Estados Unidos». Papeles de Población 24, n. 98 (2019): 61-101.

Oficina del Alto Comisionado de las Naciones para los Derechos Humanos. Principios y directrices básicos sobre el derecho de las víctimas de violaciones manifiestas de las normas internacionales de derechos humanos y de violaciones graves del derecho 
internacional humanitario a interponer recursos y obtener reparaciones. Asamblea General de Naciones Unidas, 16 de diciembre de 2005.

Oficina del Alto Comisionado de las Naciones Unidas para los Refugiados, ACNUR. Tendencias Globales. Desplazamiento forzado en 2017.

https://www.acnur.org/5b2956a04.pdf

Tendencias Globales. Desplazamiento forzado en 2019, ACNUR. https://www.acnur.org/5eeaf5664.pdf

Organización para la Cooperación y el Desarrollo Económico, OCDE. Migración Internacional en las Américas. Cuarto Informe del Sistema Continuo de Reportes sobre Migración Internacional en las Américas (SICREMI). Washington D. C.: OEA, 2017.

Organización Internacional para las Migraciones. Informe Migratorio Sudamericano No. 1. IOM: 2017. https://robuenosaires.iom.int/sites/default/files/Documentos\%20PDFs/Informe_Ten dencias_Migratorias_Am\%C3\%A9rica_del_Sur_N1_SP.pdf

Ortiz, Diana y Mauricio Viloria. Retorno voluntario, digno y con garantías. Reflexiones de la población refugiada, exiliada y víctima del conflicto armado colombiano en América Latina y el Caribe. Buenos Aires: REVICPAZ-LAC, 2018.

Presidencia de la Republica. Decreto 588 del 5 de abril de 2017. Por el cual se organiza la Comisión para el Esclarecimiento de la Verdad, la Convivencia y la no Repetición, http://es.presidencia.gov.co/normativa/normativa/DECRETO\%20588\%20DEL\%20 05\%20DE\%20ABRIL\%20DE\%202017.pdf

Roniger, Luis. Destierro y exilio en América Latina. Nuevos estudios y avances teóricos». Buenos Aires: Editorial de la Universidad de Buenos Aires, 2014.

Surraco, Leonardo. «Políticas públicas reparatorias dirigidas al universo de víctimas de graves violaciones a los derechos humanos y efectos de las prácticas sociales genocidas. - El caso de los hijos de desaparecidos y asesinados por el terrorismo de Estado en Argentina y el posicionamiento del $\mathrm{Cdh} \longrightarrow »$. Tesis de maestría. Universidad Nacional de San Martín, 2013, http://www.unsam.edu.ar/ciep/wpcontent/uploads/2013/06/Surraco_Leonardo_Tesis1.pdf

Tovar P., Hermes. «Que nos tengan en cuenta. Colonos, empresarios y aldeas: Colombia 1800-1900». Bogotá: Tercer Mundo Editores, Colcultura, 1995.

Tovar, Hermes. «Emigración y éxodo en la historia de Colombia». Amérique Latine Histoire et Mémoire 3, (2006). doi: https://doi.org/10.4000/alhim.522 XVIII". Historelo 11, n. ${ }^{\circ}$ 21 (2019): 319-349. 